\title{
Key Factors Influencing Parental Choice of School for their Children in Namakkal District
}

\author{
K. Priya \\ Head, Department of Commerce, Vivekanandha College of Arts \& Sciences (Autonomous), Tiruchengode, \\ Namakkal, Tamilnadu, India; priyakrishan17@gmail.com
}

\begin{abstract}
India is currently the world's youngest country and one of the fastest growing economies. Education is highly acclaimed as the most essential pre-requisite for human development all over the world. Parents are the primary caregivers of their children and have the responsibility of educating the children in a school of their choice. This study attempts to find out the factors influencing parental choice of school for their children. The study has disclosed that the common reasons attributed by the parents for sending their wards to government aided or unaided schools irrespective of their choice are good infrastructure, availability of trained and experienced teachers, integrity of teachers, good parent-teacher relationship and the factors relating to discipline.
\end{abstract}

Keywords: Parents' Perception, Quality, Teacher-Student Relationship

\section{Introduction}

India's present education system, especially the school sector, is in the era of globalization and is going through a phase of drastic transformation. Some parents strive to get their children admitted in one particular school for quality education, while some others withdraw their children from the same school due to dissatisfaction with its quality. Hence, there is a fierce competition among the schools to satisfy the parents with quality education. There is a mushroom growth of private schools, with cutthroat competition to maintain high success rate. They provide adequate facilities and thereby attract both the parents and students to their fold. This fierce competition among private schools has forced the government and government-aided schools also to join the race. Hence, this study attempts to find out the factors influencing parental choice of school for their children.

\section{Review of Literature}

Tangri and Moles ${ }^{1}$ examined the effects of different kinds of parent involvement on student outcomes. Watson, Brown and Swick 2 exposed the relationship among education, home support, neighborhood support, and children's achievement, whereby the children of actively supportive parents scored the highest, followed by the children of passively involved parents, and then the children of noninvolved parents.

\section{Objectives}

- To study the demographic factors of the respondents in the study area.

- To analyze the various factors affecting parental choice of school for their children.

\section{Methodology}

The present study was based on both primary and secondary data. The primary data was collected through a well structured interview schedule from 250 sample respondents in Namakkal District. The District of Namakkal was purposively chosen since it is the hub of small, medium and large size schools of all types. Convenience Sampling Technique was used in selecting the sample respondents from the target population comprising parents of school going children. The secondary data was collected from various journals, magazines, books and related websites. 


\section{Analysis and Discussion}

The respondents of the study included parents of school going children, however from various walks of life. The demographic factors of the respondents were examined by using Simple Percentage Analysis. Further, the factors affecting parental choice of school for their children were analysed by employing Factor Analysis.

\subsection{Classification of the Respondents based on Demographic Factors}

Table 1 clearly shows the classification of the respondents based on demographic factors namely age, gender, educational qualification, marital status, nature of family, size of the family and number of earning members in the family.

Table 1. Classification of respondents based on demographic factors

\begin{tabular}{|c|c|c|c|}
\hline \multicolumn{2}{|c|}{ Demographic Factors } & $\begin{array}{l}\text { Number of } \\
\text { Respondents }\end{array}$ & Percentage \\
\hline \multirow{4}{*}{ Age } & Below 30 years & 57 & 23 \\
\hline & $31-40$ years & 95 & 38 \\
\hline & $41-50$ years & 55 & 22 \\
\hline & Above 51 years & 43 & 17 \\
\hline \multicolumn{2}{|l|}{ Total } & 250 & 100 \\
\hline \multirow{2}{*}{ Gender } & Male & 123 & 49 \\
\hline & Female & 127 & 51 \\
\hline \multicolumn{2}{|l|}{ Total } & 250 & 100 \\
\hline \multirow{4}{*}{$\begin{array}{l}\text { Educational } \\
\text { Qualification }\end{array}$} & School level & 34 & 13.6 \\
\hline & College level & 90 & 36 \\
\hline & Professional & 86 & 34.4 \\
\hline & Diploma & 40 & 16 \\
\hline \multicolumn{2}{|l|}{ Total } & 250 & 100 \\
\hline \multirow{2}{*}{ Marital Status } & Married & 114 & 46 \\
\hline & Unmarried & 136 & 54 \\
\hline \multicolumn{2}{|l|}{ Total } & 250 & 100 \\
\hline \multirow{2}{*}{$\begin{array}{l}\text { Nature of } \\
\text { family }\end{array}$} & Joint family & 121 & 48.4 \\
\hline & Nuclear family & 129 & 51.6 \\
\hline \multicolumn{2}{|l|}{ Total } & 250 & 100 \\
\hline \multirow{3}{*}{$\begin{array}{l}\text { Size of the } \\
\text { family }\end{array}$} & $\begin{array}{l}\text { Upto } 3 \\
\text { members }\end{array}$ & 87 & 34.8 \\
\hline & 4-6 members & 107 & 42.8 \\
\hline & $\begin{array}{l}\text { Above } 6 \\
\text { members }\end{array}$ & 56 & 22.4 \\
\hline \multicolumn{2}{|l|}{ Total } & 250 & 100 \\
\hline
\end{tabular}

\begin{tabular}{|l|l|c|c|}
\hline \multicolumn{2}{|c|}{ Demographic Factors } & $\begin{array}{c}\text { Number of } \\
\text { Respondents }\end{array}$ & Percentage \\
\hline \multirow{2}{*}{$\begin{array}{l}\text { Number } \\
\text { of earning } \\
\text { members in } \\
\text { the family }\end{array}$} & One & 138 & 55 \\
\cline { 2 - 4 } & Two & 81 & 32.4 \\
\hline \multicolumn{2}{|c|}{ above } & 31 & 12.6 \\
\hline \multicolumn{2}{|c|}{ Total } & $\mathbf{2 5 0}$ & $\mathbf{1 0 0}$ \\
\hline
\end{tabular}

Source: Primary Data

Table 1 reveals that a maximum of $38 \%$ of the respondents are in the age group of 31-40 years, a majority of $51 \%$ of the respondents are female, a maximum of $36 \%$ of the respondents are qualified with college level of education, a majority of $54 \%$ of the respondents are unmarried, a majority of $51.6 \%$ of the respondents belong to nuclear family, a maximum of $42.8 \%$ of the respondents have 4-6 members in their family and a majority of 55\% of the respondents have only one earning member in their family.

\subsection{Factors Affecting the Parental Choice of School}

The level of agreeability towards the factors affecting parental choice of school for their children is analysed by grouping the variables using Factor Analysis. Totally 25 factors were identified based on the model of Yi Hsu and Chen Yuan-fang ${ }^{3}$. Bartlett's test of Sphericity and KaiserMayer-Olkin (KMO) measure of Sampling Adequacy are applied to test the significance of the relationship among the variables. The details of the findings are shown in the Tables 2-6.

Table 2. KMO and Bartlett's Test

\begin{tabular}{|l|l|r|}
\hline \multicolumn{2}{|l|}{$\begin{array}{l}\text { Kaiser-Meyer-Olkin Measure of Sampling } \\
\text { Adequacy }\end{array}$} & 0.905 \\
\hline Bartlett's Test of Sphericity & Approx. Chi-Square & $832.421^{*}$ \\
\hline & DF & 325 \\
\hline & Sig. & 0.000 \\
\hline
\end{tabular}

It is found from Table 2 that the $\mathrm{KMO}$ test value is 0.905 which is significant at $1 \%$ level. It implies that there exists correlation among variables. The value of the KMO index is 0.905 which is more than 0.5 and hence the application of the factor analysis for the select variables is appropriate ${ }^{4-6}$. Table 3 describes the variables and extracted communality considered for the study. 
Table 3. Variables with extracted communality

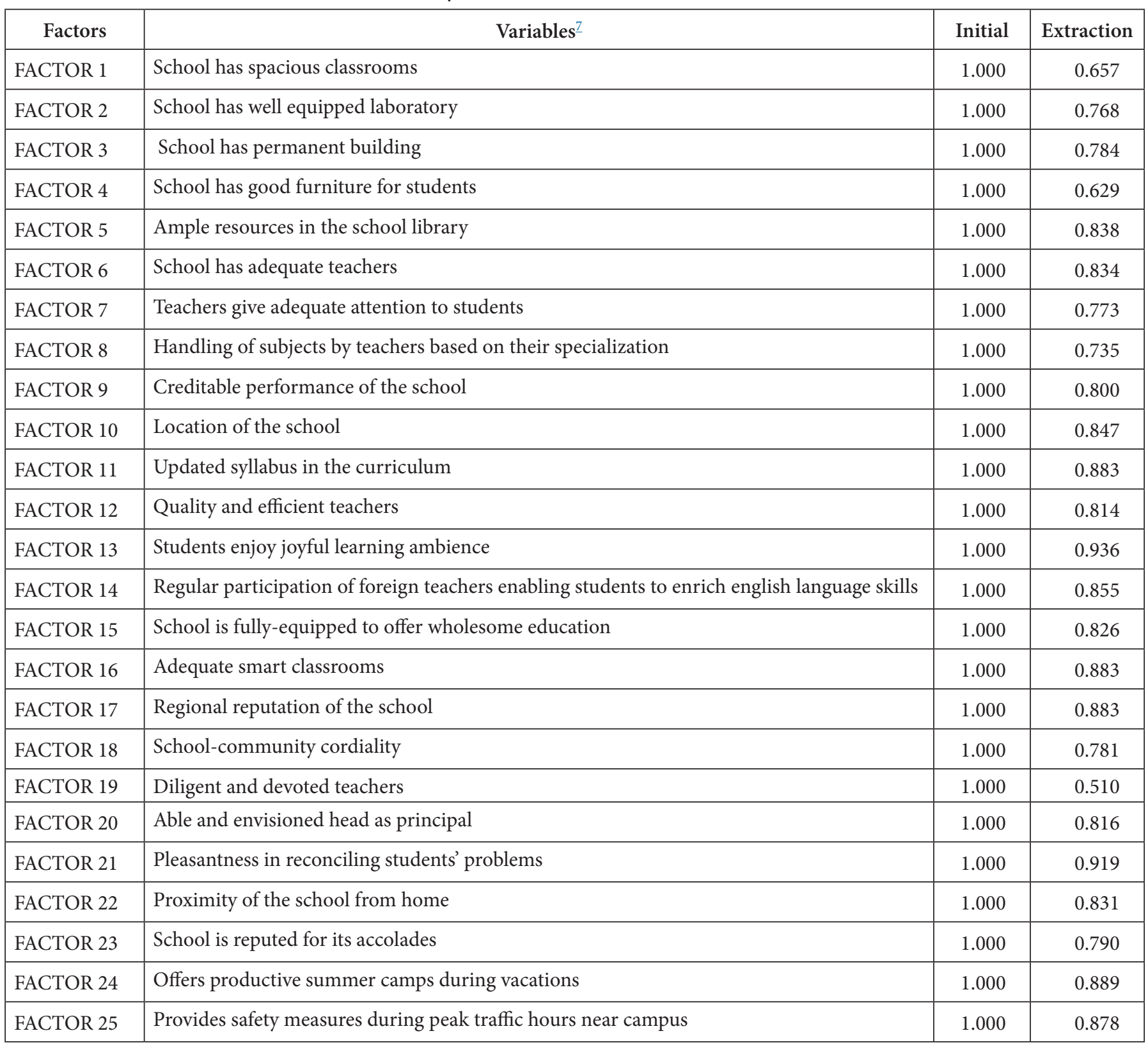

\section{Source: Primary data}

For the purpose of Principal Component Analysis (PCA), the initial assumption is taken as 1 and the extracted value is presented in extraction column of Table 3. Table 3 presents the results of Principal Component
Analysis along with the extraction values, which are more than 0.5 and hence considered for finding total variance. The total variance by successive factors is shown in Table 4.

Table 4. Total variance explained

\begin{tabular}{|c|c|c|c|c|c|c|}
\hline \multirow{2}{*}{ Component } & \multicolumn{3}{|c|}{ Initial Eigen values } & \multicolumn{3}{c|}{ Extraction Sum of Squared Loadings } \\
\cline { 2 - 7 } & Total & \% of Variance & Cumulative \% & Total & \% of Variance & Cumulative \% \\
\hline 1 & 11.519 & 46.074 & 46.074 & 11.519 & 46.074 & 46.074 \\
\hline 2 & 3.640 & 14.561 & 60.635 & 3.640 & 14.561 & 60.635 \\
\hline
\end{tabular}




\begin{tabular}{|c|c|c|c|c|c|c|}
\hline \multirow{2}{*}{ Component } & \multicolumn{3}{|c|}{ Initial Eigen values } & \multicolumn{3}{|c|}{ Extraction Sum of Squared Loadings } \\
\hline & Total & $\%$ of Variance & Cumulative \% & Total & $\%$ of Variance & Cumulative \% \\
\hline 3 & 2.072 & 8.288 & 68.923 & 2.072 & 8.288 & 68.923 \\
\hline 4 & 1.688 & 6.752 & 75.675 & 1.688 & 6.752 & 75.675 \\
\hline 5 & 1.240 & 4.960 & 80.634 & 1.240 & 4.960 & 80.634 \\
\hline 6 & 0.969 & 3.878 & 84.512 & & & \\
\hline 7 & 0.772 & 3.087 & 87.598 & & & \\
\hline 8 & 0.617 & 2.468 & 90.066 & & & \\
\hline 9 & 0.465 & 1.861 & 91.927 & & & \\
\hline 10 & 0.372 & 1.488 & 93.415 & & & \\
\hline 11 & 0.316 & 1.264 & 94.679 & & & \\
\hline 12 & 0.251 & 1.002 & 95.682 & & & \\
\hline 13 & 0.197 & 0.788 & 96.469 & & & \\
\hline 14 & 0.159 & 0.634 & 97.104 & & & \\
\hline 15 & 0.137 & 0.546 & 97.650 & & & \\
\hline 16 & 0.114 & 0.454 & 98.104 & & & \\
\hline 17 & 0.109 & 0.436 & 98.541 & & & \\
\hline 18 & 0.086 & 0.346 & 98.886 & & & \\
\hline 19 & 0.081 & 0.323 & 99.209 & & & \\
\hline 20 & 0.074 & 0.297 & 99.506 & & & \\
\hline 21 & 0.040 & 0.162 & 99.668 & & & \\
\hline 22 & 0.031 & 0.124 & 99.792 & & & \\
\hline 23 & 0.023 & 0.092 & 99.885 & & & \\
\hline 24 & 0.021 & 0.082 & 99.967 & & & \\
\hline 25 & 0.008 & 0.033 & 100.000 & & & \\
\hline
\end{tabular}

Table 4 reveals that Factor 1 accounts for $46 \%$ of variance, Factor 2 accounts for 14\%, Factor 3 accounts for 8\%, Factor 4 accounts for around 7\% and Factor 5 accounts for around $5 \%$. The number of factors to be extracted are decided based on the Eigen value being one or above for each component. Hence, the model identifies 5 factors for the given data.
Table 5 exhibits all the variables considered earlier for extraction of factors using Varimax rotation with Kaiser Normalization. All the twenty five variables have been grouped into five components and each component consists of set of factors. 
Table 5. Rotated component matrix

\begin{tabular}{|c|c|c|c|c|c|}
\hline \multirow{2}{*}{ Variables } & \multicolumn{5}{|c|}{ Component } \\
\hline & 1 & 2 & 3 & 4 & 5 \\
\hline FACTOR 13 & .896 & & & & \\
\hline FACTOR 21 & .882 & & & & \\
\hline FACTOR 22 & .836 & & & & \\
\hline FACTOR 24 & .832 & & & & \\
\hline FACTOR 25 & .822 & & & & \\
\hline FACTOR 11 & .819 & & & & \\
\hline FACTOR 14 & .812 & & & & \\
\hline FACTOR 10 & .766 & & & & \\
\hline FACTOR 20 & .674 & & & & \\
\hline FACTOR 12 & .672 & & & & \\
\hline FACTOR 05 & & .865 & & & \\
\hline FACTOR 03 & & .854 & & & \\
\hline FACTOR 06 & & .850 & & & \\
\hline FACTOR 02 & & .833 & & & \\
\hline FACTOR 07 & & .830 & & & \\
\hline FACTOR 01 & & .775 & & & \\
\hline FACTOR 04 & & .737 & & & \\
\hline FACTOR 08 & & .611 & & & \\
\hline FACTOR 16 & & & .866 & & \\
\hline FACTOR 17 & & & .799 & & \\
\hline FACTOR 15 & & & .752 & & \\
\hline FACTOR 18 & & & .751 & & \\
\hline FACTOR 19 & & & & -.697 & \\
\hline FACTOR 23 & & & & .641 & \\
\hline FACTOR 09 & & & & & .812 \\
\hline
\end{tabular}

Source: Primary data

Rotation Method: Varimax with Kaiser Normalization

It is observed from Table 5 that all the factors are having high factor loading with the values greater than 0.5 in each component and hence, selected for grouping.

Table 6 shows the results extracted from the rotated component matrix among twenty five variables. Component Factor 1 named as Institutional Culture consists of ten variables which have high influence with one another such as: Students enjoy joyful learning ambience (.896), Pleasantness in reconciling students' problems (.882), Proximity of the school from home (.836), Offers productive summer camps during vacations (.832), Provides safety measures during peak traffic hours near campus (.822), Updated syllabus in the curriculum (.819), Regular participation of foreign teachers enabling students to enrich english language skills (.812), Location of the school (.766), Able and envisioned head as principal (.674), Quality and efficient teachers (.672). Component Factor 2 named as Infrastructure consists of 8 variables namely, Ample resources in the school library (.865), School has permanent building (.854), School has adequate teachers (.850), School has well equipped laboratory (.833), Teachers give adequate attention to students (.830), School has spacious classrooms (.775), School has good furniture for students (.737) and Handling of subjects by teachers based on their specialization (.611).

Component Factor 3 named as Institutional Image consists of four variables which have influence with one another, such as: Adequate smart classrooms (.866), Regional reputation of the school (.799), School is fullyequipped to offer wholesome education (.752) and School-community cordiality (.751). 
Component Factor 4 named as Competent Teachers has found high extraction value with the factors, Diligent and devoted teachers (-.697) and School is reputed for its accolades (.641). Component Factor 5 named as Meticulous Execution has high extraction value on Creditable performance of the school (.812).

Table 6. Naming of factors

\begin{tabular}{|c|c|c|}
\hline Factors with \% of Total Variance & Variables & $\begin{array}{c}\text { Rotated } \\
\text { Factor } \\
\text { Loading }\end{array}$ \\
\hline \multirow{10}{*}{$\begin{array}{l}\text { Factor I - Institutional Culture } \\
(11.519)\end{array}$} & Students enjoy joyful learning ambience & .896 \\
\hline & Pleasantness in reconciling students' problems & .882 \\
\hline & Proximity of the school from home & .836 \\
\hline & Offers productive summer camps during vacations & .832 \\
\hline & Provides safety measures during peak traffic hours near campus & .822 \\
\hline & Updated syllabus in the curriculum & .819 \\
\hline & $\begin{array}{l}\text { Regular participation of foreign teachers enabling students to enrich } \\
\text { english language skills }\end{array}$ & .812 \\
\hline & Location of the school & .766 \\
\hline & Able and envisioned head as principal & .674 \\
\hline & Quality and efficient teachers & .672 \\
\hline \multirow{8}{*}{$\begin{array}{l}\text { Factor II - Infrastructure } \\
(3.640)\end{array}$} & Ample resources in the school library & .865 \\
\hline & School has permanent building & .854 \\
\hline & School has adequate teachers & .850 \\
\hline & School has well equipped laboratory & .833 \\
\hline & Teachers give adequate attention to students & .830 \\
\hline & School has spacious classrooms & .775 \\
\hline & School has good furniture for students & .737 \\
\hline & Handling of subjects by teachers based on their specialization & .611 \\
\hline \multirow{4}{*}{$\begin{array}{l}\text { Factor III - Institutional Image } \\
(2.072)\end{array}$} & Adequate smart classrooms & .866 \\
\hline & Regional reputation of the school & .799 \\
\hline & School is fully-equipped to offer wholesome education & .752 \\
\hline & School-community cordiality & .751 \\
\hline \multirow{2}{*}{$\begin{array}{l}\text { Factor IV - Competent Teachers } \\
(1.688)\end{array}$} & Diligent and devoted teachers & -.697 \\
\hline & School is reputed for its accolades & .641 \\
\hline $\begin{array}{l}\text { Factor V - Meticulous Execution } \\
(1.240)\end{array}$ & Creditable performance of the school & .812 \\
\hline
\end{tabular}

Source: Primary data

\section{Conclusion}

Education helps the children to build up their character and values. The main purpose of the present study is to probe the factors affecting the parents in selecting the school for the education of their children. The study revealed that the factors namely Institutional Culture, Infrastructure, Institutional Image, Competent Teachers and Meticulous Execution of the school affect the choice of preferring particular school for their wards. These factors are also responsible for making difference in the quality of education in the minds of the people.

\section{References}

1. Tangri $S$ and Moles O. Parents and the community. Educators' Handbook: A Research Perspective, edited by V. Richardson-Koehler. New York/London: Longman Press. 1987.PMid:2888029 
2. Watson T, Brown M \& Swick KJ. The relationship of parents' support to children's school achievement. Child Welfare: Journal of Policy, Practice and Program. 1983; 62(2): 175-80.

3. Yi Hsu and Chen Yuan-Fang. An analysis of factors affecting parents' choice of a Junior High School. International Journal of Business, Humanities and Technology. 2010 Feb; 3(2): 39-49.

4. Williams B, Onsman A, Brown T. Exploratory factor analysis: A five step guide for novices. Journal of Emergency
Primary Health Care (JEPHC). 2010; 8(3):1-13. Article 990399.

5. Hair J, Anderson RE, Tatham RL, Black WC. Multivariate data analysis. 4th Ed. New Jersy: Prentice Hall Inc. 1995; p. 373. PMCid:PMC2549635

6. Tabachnick BG, Fidell LS. Using multivariate statistics. Boston: Pearson Education Inc. 2007; p. 611.

7. Yi Hsu and Chen Yuan-Fang. op. cit. p. 43-4. 